\title{
Recharging RFID Tags for Environmental Monitoring Using UAVs: A Feasibility Analysis
}

\author{
Marco Allegretti, Silvano Bertoldo \\ CINFAI (Consorzio Interuniversitario Nazionale per la Fisica delle Atmosfere e delle Idrosfere), Local Unit at \\ Politecnico di Torino, Torino, Italy \\ Email: marco.allegretti@polito.it, silvano.bertoldo@polito.it
}

Received 15 January 2015; accepted 2 February 2015; published 4 February 2015

Copyright (C) 2015 by authors and Scientific Research Publishing Inc.

This work is licensed under the Creative Commons Attribution International License (CC BY). http://creativecommons.org/licenses/by/4.0/

cC) (7) Open Access

\begin{abstract}
RFID tags are used for different purposes. One of the major problems to be addressed, particularly for monitoring purposes, is their limited power autonomy. Tags must perform different tasks with limited power consumption and their batteries capacities are often too low, even if low power consumption techniques are implemented. In these operational situations tags should be kept in operation for long periods of time and the common solution is to go directly where they are installed and recharge them manually or change their batteries; alternatively, when possible, small photovoltaic (PV) panels may be adopted. This paper proposes a feasibility analysis of how it is possible to recharge a multipurpose RFID tag using a UAV (Unmanned Aerial Vehicle), which is programmed to go above the tags and recharge them. This possibility is analyzed from an energetic point of view assuming to recharge a Wireless Sensor Network (WSN) using a common commercial UAV adequately instrumented using the wireless power transfer technique.
\end{abstract}

\section{Keywords}

RFID Tags, Rechargeable Tags, UAV, Wireless Power Transfer

\section{Introduction}

Wireless Sensor Networks (WSNs) and RFID tags have attracted an increasing attention in recent years because of the large number of potential applications and of their power to perform different operations. The focus on a continuous improvement in the communication issues, the network protocols and the even smaller size of the electronic boards, together with their low power consumption of the sensors they are equipped with, allow man- 
ufacturers and researchers to study realize and deploy new RFID tags, often connected each other in a Wireless Sensor Network (WSN). At the same time, the catalog of available WSN platforms has increased to include many types of radio and processor features in order to be employed in a huge number of fields (e.g. in [1]-[10]).

Since 2008, Envisens Technologies s.r.l. (EST) has been involved in different industrial and research projects about developing new experimental WSNs and designing RFID tags for different purposes with particular focus on environmental monitoring operations. A large number of cooperative projects were completed in cooperation with the local unit of CINFAI (Consorzio Interuniversitario Nazionale per la Fisica delle Atmosfere e delle Idrosfere) at the Department of Electronic and Telecommunication (DET) of Politecnico di Torino, thus increasing its expertise in the field.

One of the major problems with a WSN made up by different RFID tags, devoted to monitoring physical and atmospheric parameters, is the limited life of the power batteries. Different techniques have been proposed to provide RFID tags with the capacity to recharge themselves through different sources of energy. They basically exploit the photovoltaic (PV) technology, the piezo-electric technology, and in recent years the wireless power transfer.

The wireless power transfer was originally proposed in a 1958 paper [11] where an early UAV was held in flight exploiting the microwave power energy transmission. The scientific and manufacturing progresses in the realization of the antennas, the so-called "rectenna", and the availability on the market of cheap UAV (commonly called, "drones") made the wireless power transfer a good solution to recharge RFID: the UAV allows recharging tags without the need of an operator on the place where they are installed, thus allowing a larger number of installations even in places not easily reachable.

In the following, a feasibility analysis is proposed to recharge the tags using a UAV with a specific and well suited version of wireless power transfer. All the analysis is made by an energetic balance point of view, without entering into details for what concern the electronic implementation.

\section{The RFID Tag and the WSN}

The first description of a multipurpose board developed was already presented in 2012 and described in details in [11]. Three evolutions of the same board, equipped with the most suitable set of sensors, tailored for a specific application, have been already used in three industrial research projects described in [4] [6] [12]. Therefore, in the following, a detailed description of the board used as network node is not reported. The electronic board used as a rechargeable RFID tags can be obtained with a slight modification to the ones already presented in the other papers. However it is important to remark their size and weight as reported in Figure 1. In fact, the lightness and the small size of the RFID tags remark their suitability for different operations,

The RFID tags are intended to be used for environmental monitoring operations and the tags can be manually distributed over an area to be monitored or even, if the area is large, or if the number of the tag is high, using a UAV which drop them where they must be placed to perform their functions. It is important to know the exact coordinates where the nodes are placed, because the UAV should eventually be able to reach them and recharge them using a GPS and software capable to travel along a predefined route.

The tags are organized in WSN with a star topology. A central node, called master node or Access Point (AP), receives and stores the information that the RFID tag (i.e. the network nodes) periodically sent to the AP. Each node communicates only with the master node and not with other tags.

The tables reported in the following paragraphs report the characteristics of the transmission system, of some of the sensors that can be installed on a simple rechargeable RFID tag and of some batteries that can be used.

\section{Evaluation of the Energy Consumption}

Before presenting the technique to recharge a RFID tag it is necessary to evaluate the energy consumption of a single tag, in order know the amount of energy necessary to recharge it (Table 1).

Some preliminary assumptions are needed:

- The single RFID tag for environmental monitoring considered in this feasibility analysis is equipped with all the five sensors reported in Table 3;

- The measurement is made by all the sensors reported in Table 3;

- The measurements are made twice a day;

- Acquired data are sent by the RFID tags to the AP of the WSN once a day (Table 2); 

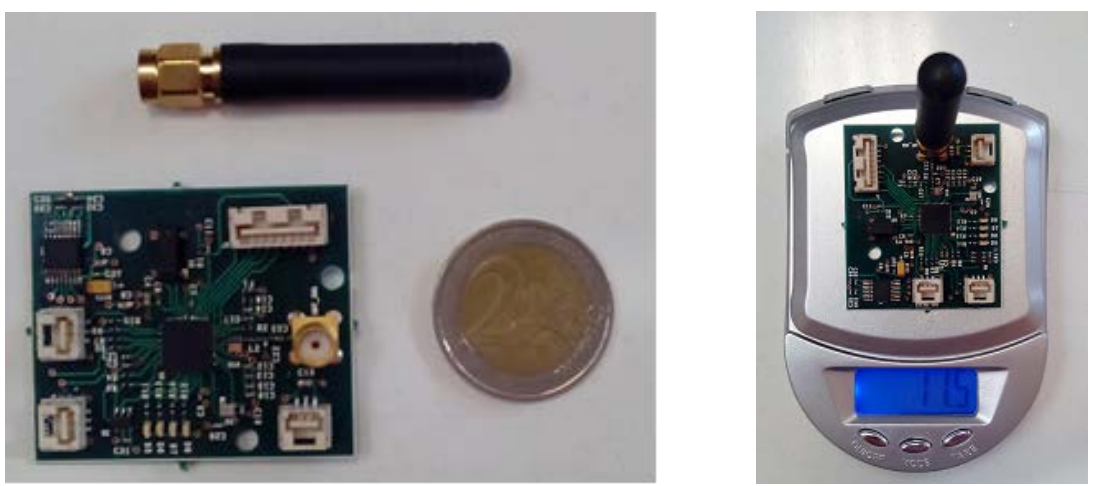

Figure 1. Size (a little larger than a $2 €$ coin) on the left and weight (less than $12 \mathrm{~g}$ ) of the latest version of RFID tags on the right, without the equipment to recharge it and without battery.

Table 1. Microcontroller (MCU) and RF transceiver characteristics.

Chip with integrated RF radio

- RF frequency:

- Standby power consumption:

- EXAMPLE:

MCU (microcontroller unit) and RF radio standalone

- RF frequency:

- Standby power consumption:

- EXAMPLE:

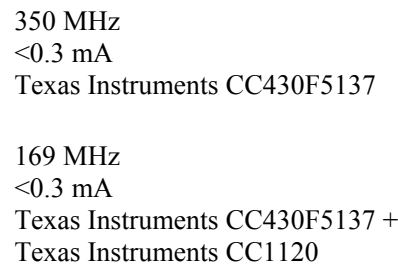

Table 2. Power consumption during the transmission of a packet from the RFID tag to the AP.

\begin{tabular}{cc} 
Power consumption & $200 \mathrm{~mA}$ \\
Duration of the transmission of 1 packet & 0.5 sminimum \\
\hline
\end{tabular}

Table 3. Example of possible sensors to be used on the RFID tags.

\section{Temperature sensor}

- Power consumption during measurement:

- EXAMPLE:

Pressure sensor

- Power consumption during measurement:

- EXAMPLE:

Humidity sensor

- Power consumption during measurement:

- EXAMPLE:

Accelerometer sensor

- Power consumption during measurement:

- EXAMPLE:

Magnetometer sensor

- Power consumption during measurement:

- EXAMPLE: $\sim 3 \mathrm{~mA}$

Pt1000 temperature sensor

$\sim 3.6 \mathrm{~mA}$

Honeywell TruStability® SSC

$<1 \mathrm{~mA}$

Honeywell HIH-4030|31

$\sim 0.15 \mathrm{~mA}$

Analog Device ADXL345

$\sim 0.15 \mathrm{~mA}$

Honeywell HMC5883L

- The AP stores all the information coming from each slave tag and it is installed in a safe place where the power supply with electric current is guaranteed;

- Only the RFID tags need to be recharged and not the AP. 


\subsection{Stand by Energy Consumption}

According to the technical data reported in Section 2, and to the preliminary assumption reported before, it is possible to evaluate the daily energy consumption when the RFID tag is in standby, as reported in the following Equation (1):

$$
W_{\text {STB }}=0.3 \times 10^{-3} \mathrm{~A} \times 3 \mathrm{~V} \times 24 \times 60 \times 60 \mathrm{~s}=77.76 \mathrm{~J}=\sim 80 \mathrm{~J}
$$

The value of $W_{S T B}=80 \mathrm{~J}$ can be reduced down to $50 \mathrm{~J}$ using low power techniques.

\subsection{Energy Consumption during a Measurement Operation}

Considering technical data reported in Section 2, and a single measurement made by all the five sensors reported in Table 3, it is possible to evaluate the energy consumption during the measurement operation as in Equation (2). The measurement lasts 10 seconds.

$$
W_{\text {MIS }}=(3+3.6+1+0.15+0.1) \times 10^{-3} \mathrm{~A} \times 3 \mathrm{~V} \times 10 \mathrm{~s}=0.235 \mathrm{~J}=\sim 0.3 \mathrm{~J}
$$

\subsection{Energy Consumption during Data Transmission}

To evaluate the energy consumption of a single RFID tag during a day, it is necessary to compute the amount of energy necessary for the data transmission form the RFID tag to the AP of the WSN. According to the information reported in Table 4 and considering a transmission which lasts $1 \mathrm{~s}$, it is possible to evaluate the energy consumption during data transmission as in the following Equation (3).

$$
W_{T X}=200 \times 10^{-3} \mathrm{~A} \times 3 \mathrm{~V} \times 1 \mathrm{~s}=0.72 \mathrm{~J}=1 \mathrm{~J}
$$

\subsection{Energy Consumption during a Day}

Considering Equation (1), Equation (2) and Equation (3), the energy consumption of the RFID tag during an entire day of work is simply the sum of all the previous quantities, and it is evaluated as in Equation (4).

$$
W_{D A Y}=W_{S T B}+W_{M I S}+W_{T X}=50+0.3+1=51.3 \mathrm{~J}=\sim 50 \mathrm{~J}
$$

It is to note that the largest energy consumption is due to the standby state of the RFID tag. Therefore, in order to further reduce the energy consumption, it is important to develop new techniques capable to reduce as much as possible the energy consumption of the sensors and of the microcontroller unit (MCU) when they are not measuring.

Table 5 reports the energy consumption computed over different time interval.

\subsection{Energy Available at the Battery}

The proposed battery guarantees the power supply for a period of time longer than 1 month, which can be enough for some specific operation. However, if it is necessary to monitor some specific parameters for a long period, as an environmental monitoring operation can require, it could be necessary to recharge or replace batteries. A possible technique exploiting UAV, without the need of an operator who manually recharges the tags at the site, is presented in the following section. The same techniques allow also installing the tag in dark environment where the use of PV panels is not possible.

\section{Recharge the RFID Tags with Wireless Power Transfer and UAV}

The idea proposed in the present work, is to use a UAV to recharge the battery of a RFID with a rectenna on it. Some basic assumptions may be made:

- The UAV reaches a point at the vertical of the rectenna of the RFID tag at a height of about $5 \mathrm{~m}$. It should be kept in hovering for the time needed to completely recharge the tag;

- The RFID tag must be recharged every 3 days. The simple Lithium CR2032 battery allows the tag to be operative for much longer than 3 days. However, in order not to spend too much time hovering above the RFID tag, and not to discharge the UAV batteries too much, we assume the UAV is going to recharge the battery much more frequently; 
Table 4. Example of a compact rechargeable battery to be used for the RFID tags.

\begin{tabular}{|c|c|}
\hline $\begin{array}{l}\text { Lithium battery, CR2032 } \\
\text { - Capacity: } \\
\text { - Voltage: } \\
\text { - Size: } \\
\text { - Available energy: } \\
\text { - EXAMPLE: }\end{array}$ & $\begin{array}{l}225 \mathrm{mAh} \\
3 \mathrm{~V} \\
20 \times 3.2 \mathrm{~mm} \\
2400 \mathrm{~J} \\
\text { Panasonic CR2032 }\end{array}$ \\
\hline Time interval & Energy consumption $[\mathrm{J}]$ \\
\hline 1 day & 50 \\
\hline 3 days & 150 \\
\hline 4 days & 200 \\
\hline 10 days & 500 \\
\hline 1 year & 18,250 \\
\hline 10 years & 182,500 \\
\hline
\end{tabular}

- An elementary rectenna to beused may have the characteristics reported in [13] and summarized in Table 6;

- In the calculation of the energy received by the RFID tag, it is necessary to add some further system losses equal to $2 \mathrm{~dB}$ (in linear units, the losses are equal to 1.5) representing the losses of the electronic circuitry.

Considering an available area for the rectenna system (the set of elementary rectennas) of $10 \mathrm{~cm} \times 10 \mathrm{~cm}$ on the RFID tag, it is possible to use 10 elementary rectennas of the same type as the one described in Table 6.

If we assume to irradiate the whole rectenna system with the same operative power density reported in [13], a time $T=15$ minutes is needed for the rectenna to restore the initial energy level (Equation (5)).

$$
W_{R E C T}=2.5 \times 10^{-3} \mathrm{~W} / \mathrm{cm}^{2} \times 100 \mathrm{~cm}^{2} \times 1.5^{-1} \times T=150 \mathrm{~J}
$$

A small UAV cannot hover on a single RFID for 15 minutes. Furthermore working at a frequency of $2.4 \mathrm{GHz}$ at $5 \mathrm{~m}$ from the target implies either the use of a too large antenna to avoid dissipating the largest part of the power in space around and away from the target.

Evidently a completely different approach is needed. Let us assume to use a rectenna operating at a frequency of $35 \mathrm{GHz}$ (designed since 1992 [14]). In this case, a small distance between UAV and the RFID tag does not cause significant atmospheric absorption.

In order to recharge the RFID tag in a time $T=10 \mathrm{~s}$, assuming to use a $10 \mathrm{~cm} \times 10 \mathrm{~cm}$ rectenna section, a power density $\mathrm{S}=0.15 \mathrm{~W} / \mathrm{cm}^{2}$ is needed, corresponding to an electric field of the order of $1500 \mathrm{~V} / \mathrm{m}$. It corresponds in turn to a voltage drop across the rectenna of $150 \mathrm{~V}$.

It is to be note that at a frequency $f=35 \mathrm{GHz}$ an antenna with approximately a $20 \mathrm{~cm}$ diameter is enough to generate a $3^{\circ} \mathrm{HPBW}$ (Half Power Beam Width), sufficiently larger than the assumed rectenna system size to easily illuminate the whole rectenna system itself.

During the $10 \mathrm{~s}$ transmission, the total emitted power is approximately equal to $150 \mathrm{~W}$. Evidently the system in this way will operate at the physical limit. However, by increasing the time the UAV will stay on the RFID tag it is possible to reduce the total emitted power, thus allowing the tag circuitry to operate without problem.

Let us consider a UAV equipped with a commercial battery with a voltage of $12 \mathrm{~V}$ and $6800 \mathrm{mAh}$, which is commonly used as power source for UAV systems.

Considering the energy consumption of 3 days for a single RFID tag (150 J, Table 5) and considering to have a WSN made by 10 RFID nodes equipped with a rectenna operating at frequency of $35 \mathrm{GHz}$, it is possible to assume that a time $T=10$ minutes can be a good estimation to recharge one single tag, which allow also to be under the exposure limit for a controlled environment as reported in the "IEEE Standard for Safety Levels with Respect to Human Exposure to Radiofrequency Electromagnetic Fields" [15]. 
Table 6. Rectenna characteristics.

\begin{tabular}{|c|c|}
\hline Frequency: & $\sim 2.4 \mathrm{GHz}$ \\
\hline Size: & $53 \mathrm{~mm} \times 22 \mathrm{~mm}$ \\
\hline Conversion efficiency $\eta$ & $75 \%$ \\
\hline Operative power density $\mathrm{S}$ & $2.5 \mathrm{~mW} / \mathrm{cm}^{2}$ \\
\hline
\end{tabular}

The power needed to recharge the tag, with a time $T=1800 \mathrm{~s}$ is given by Equation (6):

$$
P_{R I C}=\frac{150 \mathrm{~J}}{600 \mathrm{~s}}=0.25 \mathrm{~W}
$$

Considering further losses equal to $2 \mathrm{~dB}$ due to the tag electronic circuitry, the RFID tag rectenna system should receive about $0.5 \mathrm{~W}$. It means that in 10 minutes, the drone will spend $300 \mathrm{~J}$ of the energy available at the battery to load a single RFID tag. If the WSN is made by 10 tags, the amount of energy will be $3000 \mathrm{~J}$, which could be approximate to $4000 \mathrm{~J}$ considering some further, not previously analyzed, losses.

The energy available at the battery of the UAV is given by the following Equation (7):

$$
W_{U A V}=12 \mathrm{~V} \times 6.8 \mathrm{~A} \times 60 \times 60 \mathrm{~s}=293760 \mathrm{~J}=\sim 290000 \mathrm{~J}
$$

Considering the amount of energy to recharge the RFID tags, $286,000 \mathrm{~J}$ are still available to make the UAV flight and moving from one WSN node to the other. Usually a common UAV has flight autonomy of about 20 minutes. Considering the amount of energy to recharge 10 tags, the UAV is still capable to flight for almost 19 minutes, thus allowing both the RFID tag recharge operations and the flight of the UAV.

\section{RFID Tag Localization}

The proposed solution to recharge the RFID tag using the UAV implies to know the exact GPS coordinate where the tags are placed. Moreover, the UAV must be equipped with a GPS navigator and software capable to follow a predefined route and hovering above. Landing on top of tags can be improved possible by using c sophisticated imaging techniques.

The idea is to make the UAV flight over each tag, make it landing over them and to keep it on the rectenna system of the tag for the time necessary to recharge the battery. When the battery of the RFID tag is fully recharged the UAV can flight to the next tag according to its pre-programmed route. In this way it is possible to reduce the amount of transmitted power from the UAV, to avoid electric field exposure problems, to use an antenna with compact size, and to allow the UAV to load a set of RFID tags during the day. Moreover a single operator is needed with the important tasks to appropriately programming the UAV route and equips the UAV with the most suitable, and fully charged, battery.

\section{Conclusions}

In the present work the energy consumption of a RFID tag designed for environmental monitoring operation is evaluated. A solution to recharge the RFID tag is proposed, using an automatic UAV equipped with a rectenna system. The energy balance computed, considering a WSN made by 10 tags, demonstrates the feasibility of the proposed solution. However, this paper does not present any technological solution to realize the rectenna system, the elementary rectenna, the RFID tag electronic circuitry and the antenna build on the UAV.

Assuming that all the proposed solutions are feasible, the techniques can be implemented in a practical situation where a real WSN is installed. Of course some further improvements can be studied and adopted to allow the UAV to land exactly on the RFID tag which must be recharged, to allow the UAV to transfer the maximum amount of energy possible to the tag, and to design the rectenna and the electronic circuitry to correctly receive the power necessary to recharge the batteries.

\section{Acknowledgements}

The present feasibility analysis is one of the results of a joint industrial research project between the local unit of CINFAI (Consorzio Interuniversitario Nazionale per la Fisica delle Atmosfere) at the Department of Electronic and Telecommunication at Politecnico di Torino and EST (Envisens Technologies s.r.1.) within the project 
“COMODO” financed by the Regione Piemonte, Italy.

\section{References}

[1] Galluzzi, V. and Herman, T. (2012) Survey: Discovery in Wireless Sensor Networks. International Journal of Distributed Sensor Networks, 2012, Article ID: 271860, 12 p. http://dx.doi.org/10.1155/2012/271860.

[2] Lucianaz, C., Rorato, O., Allegretti, M., Mamino, M., Roggero, M. and Diotri, F. (2011) Low Cost DGPS Wireless Network. IEEE-APS Topical Conference on Antennas and Propagation in Wireless Communications (APWC), Torino, 12-16 September 2011, 792-795.

[3] Gabella, M., Notarpietro, R., Bertoldo, S., Prato, A., Lucianaz, C., Rorato, O., Allegretti, M. and Perona, G. (2012) A Network of Portable, Low-Cost, X-Band Radars. In: Bech, J., Ed., Doppler Radar Observations-Weather Radar, Wind Profiler, Ionospheric Radar, and Other Advanced Applications, Intech, Rijeka, 175-202.

[4] Rorato, O., Greco, G., Bertoldo, S., Lucianaz, C., Allegretti, M., Curtaz, M., Roasio, A., Barone, S. and Perona, G. (2014) An Ad-Hoc RFID Tag for Glaciers Monitoring. IEEE-APS Topical Conference on Antennas and Propagation in Wireless Communications (APWC), Palm Beach, 3-9 August 2014, 864-867.

[5] Martinez, K., Ong, R. and Hart, J. (2004) Glacsweb: A Sensor Network for Hostile Environments. First IEEE Communications Society Conference on Sensor and Ad Hoc Communications and Networks, Santa Clara, 4-7 October 2004, 81-87.

[6] Bertoldo, S., Rorato, O., Lucianaz, C. and Allegretti, M. (2012) A Wireless Sensor Network Ad-Hoc Designed as Anti-Theft Alarm System for Photovoltaic Panels. Wireless Sensor Network, 4, 107-112. http://dx.doi.org/10.4236/wsn.2012.44014

[7] Le Sage, T., Bindel A., Conway, P., Justham, L., Slawson, S. and West, A. (2011) Embedded Programming and Real-Time Signal Processing of Swimming Strokes. Sports Engineering, 14, 1-14. http://dx.doi.org/10.1007/s12283-011-0070-7

[8] Keshtgari, M. and Deljoo, A. (2012) A Wireless Sensor Network Solution for Precision Agriculture Based on Zigbee Technology. Wireless Sensor Network, 4, 25-30. http://dx.doi.org/10.4236/wsn.2012.41004

[9] Delgui, A. and Proth, J.M. (2008) RFID Technology in Supply Chain Management: State of the Art and Perspective, 17th IFAC World Congress, Seoul, 11-16 July 2008, 4464-4475. http://dx.doi.org/10.3182/20080706-5-KR-1001.00753

[10] Allegretti, M. and Bertoldo, S. (2013) Cars as a Diffuse Network of Road-Environment Monitoring Nodes. Wireless Sensor Network, 6, 184-191. http://dx.doi.org/10.4236/wsn.2014.69018

[11] Rorato, O., Lucianaz, C., Bertoldo, S., Allegretti, M. and Perona, G. (2012) A Multipurpose Node for Low Cost Wireless Sensor Network. IEEE APWC 2012, Cape Town, 2-7 September 2012, 247-250, ISBN: 9781467304030. http://dx.doi.org/10.1109/APWC.2012.6324911

[12] Rorato, O., Bertoldo, S., Lucianaz, C., Allegretti, M. and Notarpietro, R. (2013) An Ad-Hoc Low Cost Wireless Sensor Network for Smart Gas Metering. Wireless Sensor Network, 5, 61-66. http://dx.doi.org/10.4236/wsn.2013.53008

[13] Zhang, F., Liu, X., Meng, F., Wu, Q., Lee, J., Xu, J., Wang, C. and Kim, N. (2014) Design of a Compact Planar Rectenna for Wireless Power Transfer in the ISM Band. International Journal of Antennas and Propagation, 2014, 9 p. http://dx.doi.org/10.1155/2014/298127

[14] Yoo, T., McSpadden, J. and Chang, K. (1992) 35 GHz Rectenna Implemented with a Patch and a Microstrip Dipole Antenna. Microwave Symposium Digest, IEEE MTT-S International, 1, 345-348. http://dx.doi.org/10.1109/MWSYM.1992.187983

[15] IEEE Standard for Safety Levels with Respect to Human Exposure to Radiofrequency Electromagnetic Fields, $3 \mathrm{kHz}$ to $300 \mathrm{GHZ}$, IEEE Std C95.1-2005 
Scientific Research Publishing (SCIRP) is one of the largest Open Access journal publishers. It is currently publishing more than 200 open access, online, peer-reviewed journals covering a wide range of academic disciplines. SCIRP serves the worldwide academic communities and contributes to the progress and application of science with its publication.

Other selected journals from SCIRP are listed as below. Submit your manuscript to us via either submit@scirp.org or Online Submission Portal.
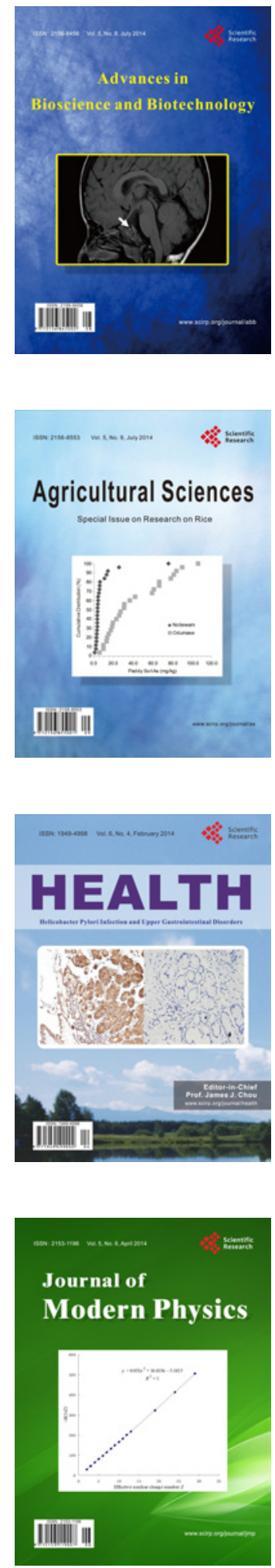
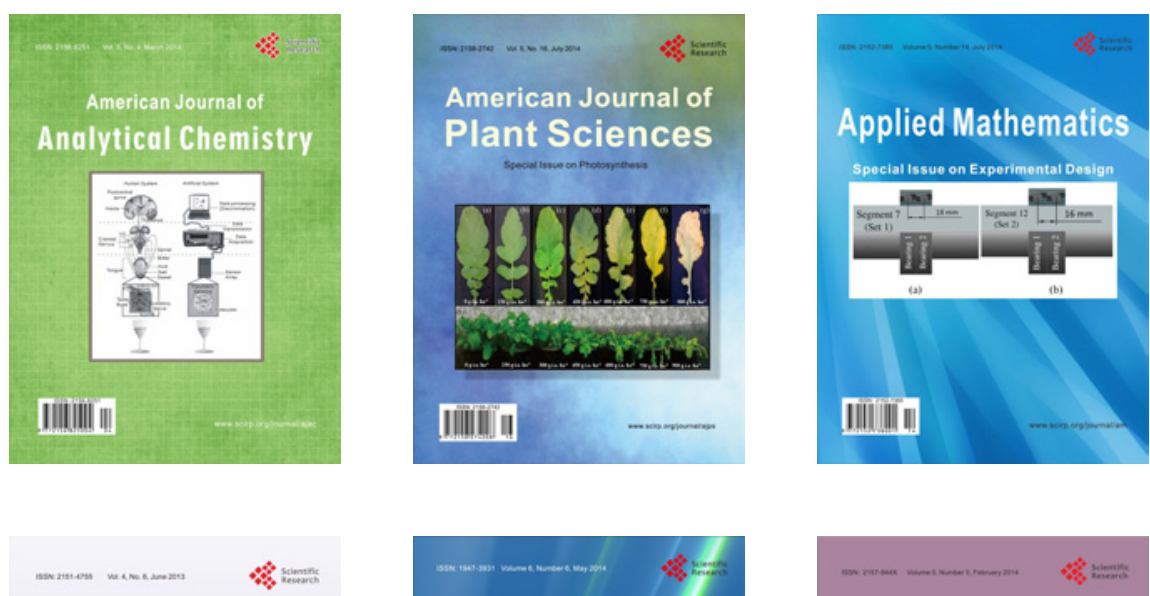

Creative Education
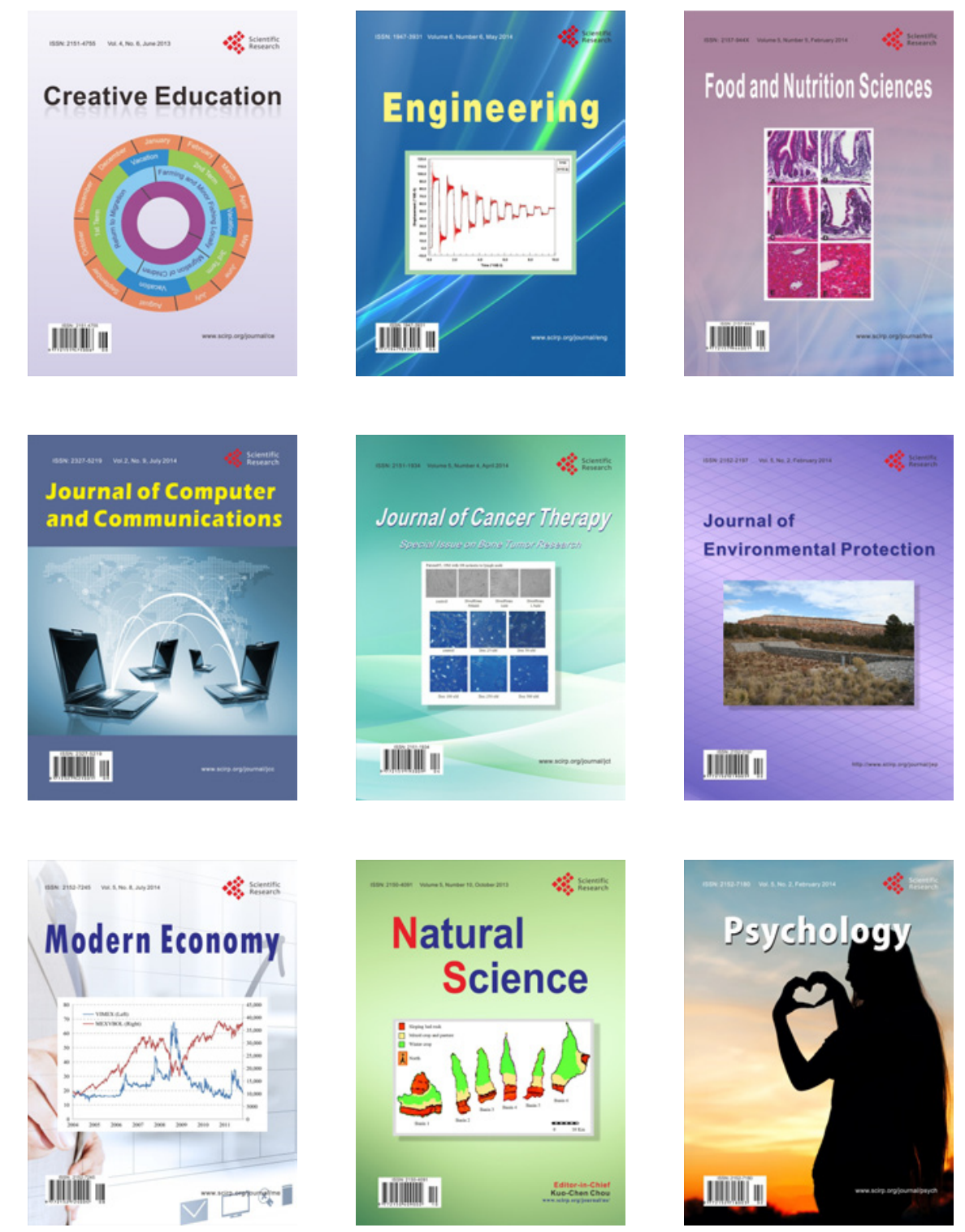